\title{
Editorials
}

\section{Are the millennium development goals on target?}

BMJ 2010; 341 doi: http://dx.doi.org/10.1136/bmj.c5045 (Published 14 September 2010) Cite this as: BMJ 2010;341:c5045

- Article

- Related content

- Metrics

- Responses

- Peer review

-

Joy Lawn, director, global evidence and policy

\section{$\underline{\text { Author affiliations }}$}

joylawn@yahoo.co.uk

Successes and shortfalls so far make 2010 a tipping point especially for maternal and neonatal survival

At the United Nations Millennium Summit in 2000, 189 member states, including 147 heads of state, committed to the Millennium Development Goals (MDGs). These eight interlinking goals tackle the global plagues of poverty, hunger, lack of education, and ill health and provide a unique opportunity to accelerate progress for the world's poorest families (fig $\underline{\Downarrow}$ ). On 20-22 September 2010, world leaders meet to assess progress over the past decade and set priorities for the five years before the MDG deadline of 2015.

Multiple reports have been published throughout the year, but are the promises of the MDGs connecting to progress?1 At the heart of the MDGs are goals 4 for child survival and 5 for maternal survival. Are fewer mothers, newborns, and children dying? Is essential health care improving for the poorest? Or are the numbers themselves a battleground? Maternal statistics have become as political as HIVIAIDS statistics were in the past. 2

Despite superficial differences, common themes exist in the new data-a mixture of success and shortfalls. The good news is that progress for child mortality is accelerating. Although fewer children died this year than last year, it is unacceptable that each year 8.8 million children still die, including 3.6 million newborns. 3 However, progress for neonatal and maternal mortality seems to be lagging, with successes such as China being the exception rather than the rule. The proportion of deaths in under 5 year olds accounted for by newborn deaths has increased from $37 \%$ in 2000 to $41 \%$ in 2008 . Yet few UN documents on MDG 4 even mention neonatal care.4 Each year upwards of 342900 women die of maternal causes, 5 depending on which report is subscribed to. Each year 60 million births occur at home and this is a critical determinant for maternal and newborn survival. 6

An independent data and accountability movement called Countdown to 2015 tracks progress in the 68 countries with over $95 \%$ of maternal and child deaths. 7 For MDG 4 towards child survival, 19 countries 


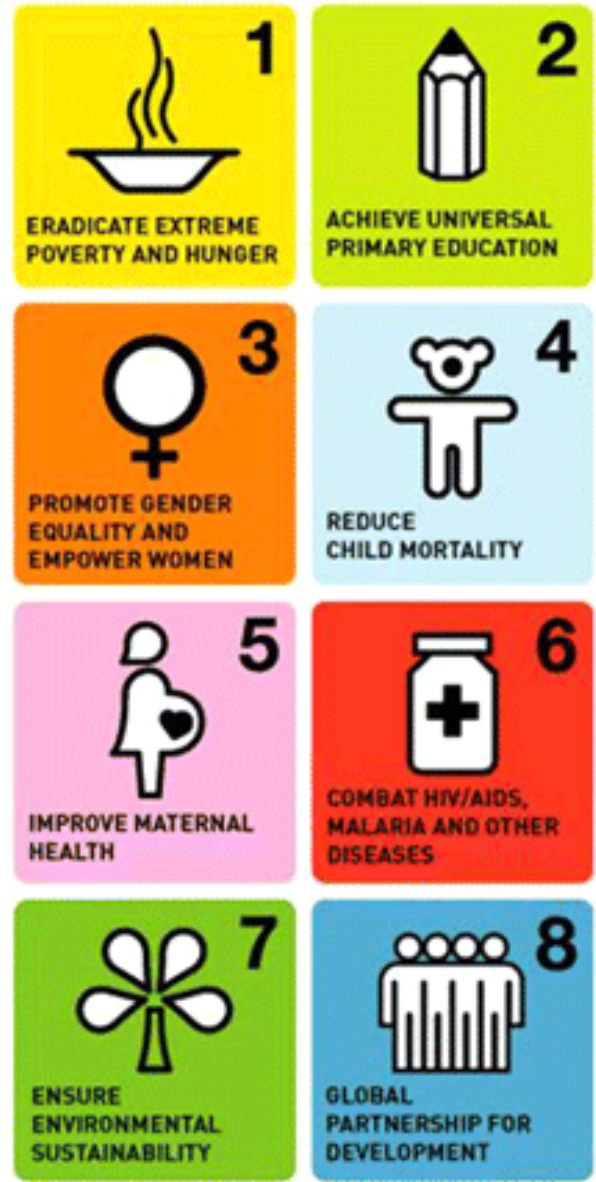

The Millennium Development Goals: eight interlinked development and health goals set in 2000 (baseline 1990, target 2015)

"www.un.org"

Download figure

Open in new tab

Download powerpoint

are now on track and 47 have accelerated progress since 2000. Even some of the poorest countries are now on track, including four low income countries in sub-Saharan Africa-notably Botswana and Malawi, although both have a high prevalence of HIV. Understanding why these countries have succeeded will hold many lessons for their neighbours and for what now must be repeated for maternal and neonatal survival.

Health outcome gaps are increasing between the richest and poorest countries. Some countries are being left far behind, especially in Africa. With only $11 \%$ of the world's population, Africa carries more than half of all maternal and child deaths, two thirds of the global AIDs burden, and $90 \%$ of deaths from malaria.8 Within countries there are also important gaps for the poorest-if all the families in Nigeria had the same neonatal mortality rate as the richest $20 \%$, then 127000 fewer newborns would die each year.9 Governments should be held to account for reaching their poorest and the most vulnerable citizens. The latest UNICEF Progress for Children publication has an important focus on equity and closing gaps for the poorest.10 
Reducing these needless deaths is dependent on high and equitable coverage of basic interventions. Rapid increases in coverage have been achieved for some well funded and vertically delivered interventions such as immunisations, prevention of mother to child transmission of HIVIAIDS, and malaria interventions. Almost 200 million bednets were distributed between 2007 and 2009, more than half of the 350 million required.10

However, progress remains too slow for some interventions, including the highest impact interventions, such as safe care at birth and treatment of neonatal and childhood illness. Family planning and contraception are at risk of falling off the agenda despite being rapid and cost effective ways to reduce maternal and child deaths and accelerate development.7 Many UN documents focus on the interventions that already receive the most attention11 rather than those with the greatest potential effect in the next five years.

Donor funding for health has increased by $105 \%$ since 2003 , and funding for maternal and child health has kept pace, but still does not reflect the size of the burden.12 For example, the combined HIV, tuberculosis, and malaria burden of around 3 million deaths (including 201000 deaths from AIDS and 732000 from malaria in children under 53) is only a third of the size of the burden of maternal, newborn, and child death, yet it receives vastly more funding. The UN Secretary General's Joint Plan of Action for Women and Children aims to redress this investment gap and involve wider stakeholders, such as civil society and private sector.

So what are the key priorities in the next crucial five years? The first is to use data at national or ideally subnational level, considering the main causes of death, coverage, and quality and equity gaps, and to focus on implementing the interventions with the greatest impact especially for care at birth and the first few days after birth. Rapid reductions in mortality are possible even with $20 \%$ increases in coverage of targeted interventions. 8 National7 and subnational9 data are a key to designing programmes and tracking their progress.

The second priority is to innovate, especially for service delivery. Most of the countries with the highest mortality rates have fewer than 0.5 skilled health personnel per 1000 population, compared with over 10 per 1000 in the UK. This will require task shifting within the health system and bringing care closer to home-for example, using community health workers for appropriate care at home. $\underline{\underline{T}}$ The third priority is to target the poor and remove financial barriers such as user fees for maternity and child health services, and not to leave lessening disparity to chance and "trickle down" philosophies. The final priority is to strengthen accountability for donor governments, for low income country governments, and for all partners including the UN.

The year 2010 is a tipping point. We are the first generation to have the tools and the funding to transform lives for the world's poorest families. Why should a mother in rural Nigeria die giving birth? Why should a baby in India die of birth complications? Why should a child in Ethiopia die of pneumonia? The underlying question is whether the world's leaders, and all of us, will deliver on our promises.

\section{Priorities to speed up progress for maternal, newborn, and child survival}




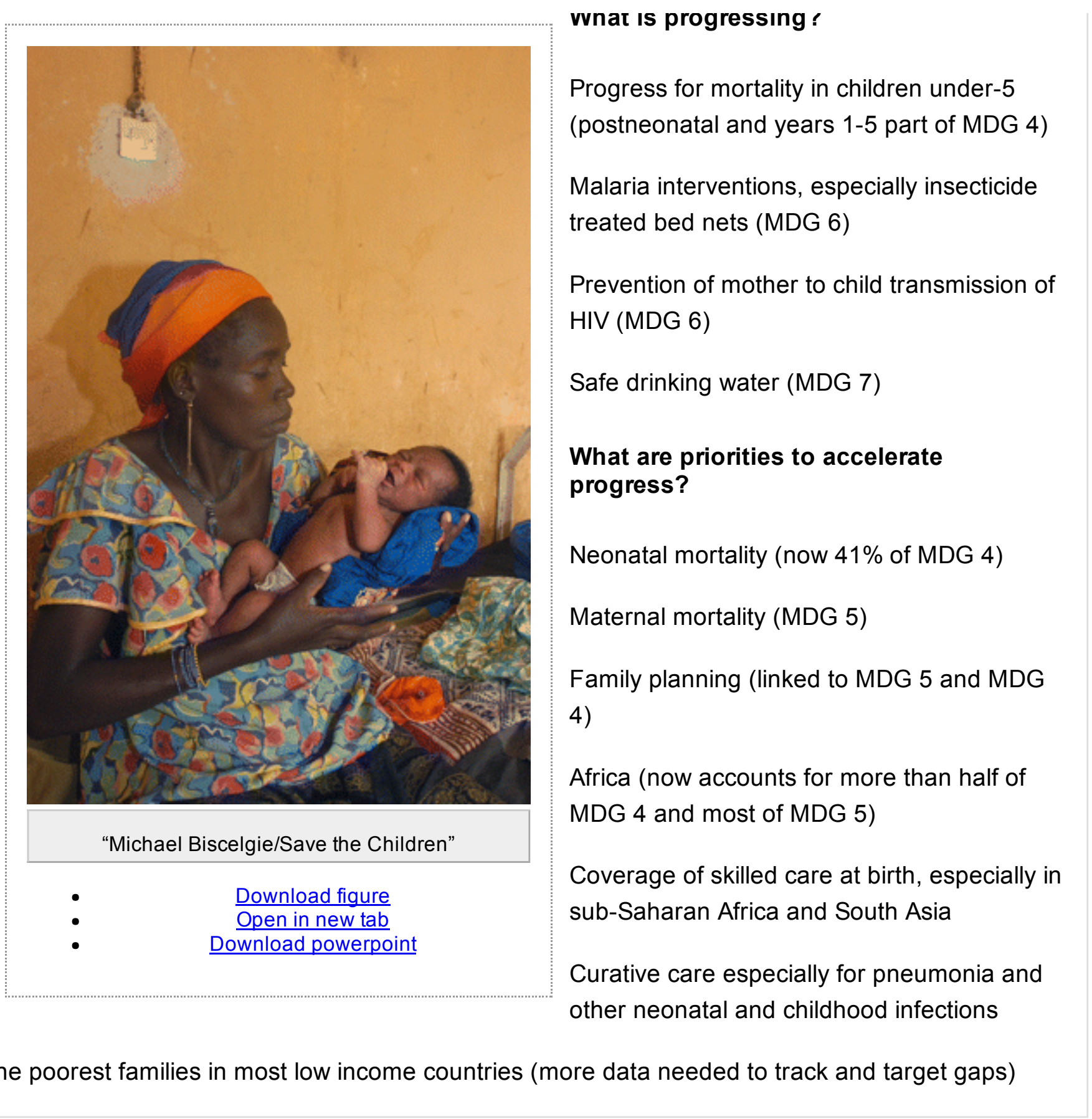

\section{Notes}

Cite this as: BMJ 2010;341:c5045

\section{Footnotes}

- Competing interests: All authors have completed the Unified Competing Interest form at www.icmje.org/coi disclosure.pdf (available on request from the corresponding author) and declare: no support from any organisation for the submitted work; no financial relationships with any organisations that might have an interest in the submitted work in the previous 3 years; no other relationships or activities that could appear to have influenced the submitted work.

- Provenance and peer review: Commissioned, not externally peer reviewed. 


\section{Keterences}

1. $\downarrow$ United Nations report of the Secretary General. Keeping the promise: a forward-looking review to promote an agreed action agenda to achieve the Millennium Development Goals by 2015. Report of the follow-up to the outcome of the Millennium Summit. United Nations, 2010. www.un.org/ga/search/view doc.asp? symbol=A/64/665.

2. $\downarrow$ Horton R. Maternal mortality: surprise, hope, and urgent action. Lancet2010;375:1581-2. CrossRef Medline Web of Science

3. $\lrcorner$ Black RE, Cousens S, Johnson HL, Lawn JE, Rudan I, Bassani DG, et al. Global, regional, and national causes of child mortality in 2008: a systematic analysis. Lancet2010;375:1969-87. CrossRef Medline Web of Science

4. $\lrcorner$ Shiffman J. Issue attention in global health: the case of newborn survival. Lancet2010;375:2045-9. CrossRef Medline Web of Science

5. $\downarrow$ Hogan MC, Foreman KJ, Naghavi M et al. Maternal mortality for 181 countries, 1980-2008: a systematic analysis of progress towards Millennium Development Goal 5. Lancet2010;375:1609-23. CrossRef Medline Web of Science

6. $\downarrow$ Darmstadt GL, Lee AC, Cousens S, Sibley L, Bhutta ZA, Donnay F, et al. 60 million non-facility births: who can deliver in community settings to reduce intrapartum-related deaths? Int J Gynaecol Obstet2009;107(suppl 1):S89-112. www.ijgo.org/issues/contents?issue key=S0020-7292\%2809\%29X0010-X. Medline

7. $\downarrow$ Countdown to 2015. Countdown to 2015 decade report (2000-2010): taking stock of Maternal, Newborn and Child Survival. WHO and UNICEF, 2010. www.countdown2015mnch.org/reports-publications/2010-report.

8. $\downarrow$ Friberg IK, Kinney MV, Lawn JE, Kerber KJ, Odubanjo MO, Bergh AM, et al. Sub-Saharan Africa's mothers, newborns, and children: how many lives could be saved with targeted health interventions? PLoS Med2010;7:e1000295. CrossRef Medline

9. $\downarrow$ Federal Republic of Nigeria Ministry of Health. Saving newborn lives in Nigeria: situation analysis and action plan for newborn health in the context of the integrated MNCH strategy. FMOH, 2009.

http://www. healthynewbornnetwork.org/resource/saving-newborn-lives-nigeria-situation-analysis-and-actionplan-newborn-health-context-inte

10. $\downarrow U N$ UNCEF. Progress for children: achieving the MDGs with equity. UNICEF, 2010. www.unicef.org/publications/index 55740.html.

11. $\downarrow U N D P$. What will it take to achieve the MDGs? UNDP, 2010. http://content.undp.org/go/cmsservice/stream/asset/?asset id $=2620072$

12. $\downarrow$ Pitt C, Greco G, Powell-Jackson T, Mills A. Countdowm to 2015: assessment of the official development assistance to maternal, newborn and child health, 2003-08. Lancet [forthcoming].

- f Like 0

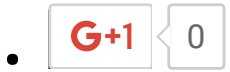

\section{Article tools}

\section{4 responses}

